\title{
Análise dos Atrativos Naturais da Serra dos Alves, Senhora do Carmo, Itabira, MG, Brasil: uma contribuição para o desenvolvimento do turismo sustentável
}

Raphaela Silva de Oliveira ${ }^{a}$ Juni Silveira Cordeirob

\begin{abstract}
Resumo
0 turismo é uma modalidade econômica que busca promover a preservação dos recursos naturais e o desenvolvimento social de uma comunidade, abrangendo os aspectos peculiares de uma região, como natureza, história e até mesmo elementos geológicos. Dessa forma, este trabalho objetivou avaliar o potencial turístico de trilhas na região da Serra dos Alves em Senhora do Carmo, distrito de Itabira (MG), bem como verificar a infraestrutura existente no local para atendimento ao turismo. Assim, análise documental e entrevistas foram utilizadas como instrumentos de coleta de dados e observação. Com relação ao potencial das trilhas, podem ser citados aspectos negativos, como a falta de sinalização para acesso aos pontos turísticos. Porém, todos os atrativos apresentaram grande possibilidade para desenvolvimento de diversas modalidades turísticas, entre as quais podem ser ressaltadas o ecoturismo, o geoturismo e o turismo de aventura.

Palavras-chave: Atividades turísticas; Ecoturismo; Sustentabilidade; Trilha; Senhora do Carmo.
\end{abstract}

\begin{abstract}
Analysis of Natural Attractions in Serra dos Alves, Senhora do Carmo, Itabira, MG, Brazil: a contribution to the development of sustainable tourism

Tourism is an economic modality that aims to promote the conservation of natural resources and the social development of a community, including specific aspects that a region has - such as nature, history and even geological elements. Thus, this study aimed to assess tourism potential of trails in Serra dos Alves, Senhora do Carmo, Itabira, MG, Brazil, as well as to verify the existing local infrastructure concerning tourism. Documentary analysis and interviews were used as instruments of data collection and observation. Regarding the tourism potential of the trails, negative aspects can be mentioned such as the lack of signage to access the tourist sites. However, all of them presented great potential for developing different tourism modalities, among which ecotourism, geotourism and adventure tourism can be highlighted.
\end{abstract}

Keywords: Tourist activities; Ecotourism; Sustainability; Trail; Senhora do Carmo.

a. Graduada em Engenharia Ambiental pela Fundação Comunitária de Ensino Superior de Itabira (Funcesi). Itabira, Minas Gerais, Brasil. E-mail: rapha.silva17@yahoo.com.br

b. Mestre em Geologia Regional pela Universidade Federal de Minas Gerais (UFMG). Graduada em Geologia pela UFMG. Professora da Fundação Comunitária de Ensino Superior de Itabira. Itabira, Minas Gerais, Brasil. E-mail: juni.cordeiro@funcesi.br 


\section{Resumen}

Un Análisis de los Atractivos Naturales de la Serra dos Alves, Senhora do Carmo, Itabira, MG, Brasil: una contribución al desarrollo del turismo sostenible

El turismo es un modo económico que se propone promover la conservación de los recursos naturales y el desarrollo social de una comunidad, que incluye los aspectos específicos de una región: su naturaleza, su historia, sus elementos geológicos, entre otros. Por lo tanto, este estudio tuvo como objetivo evaluar el potencial turístico de senderos en la región de la Serra dos Alves en Senhora do Carmo, Itabira (MG), Brasil, así cowmo verificar la infraestructura existente en el lugar para atender al turismo. Así se utilizaron como instrumentos para la observación y recopilación de datos, el análisis de documentos y entrevistas. En cuanto al potencial turístico de los senderos, se puede citar como aspecto negativo, por ejemplo, la falta de señalizadores a los lugares turísticos. Todos los lugares turísticos en este lugar presentan un gran potencial para el desarrollo de las diferentes modalidades turísticas, a ejemplo del ecoturismo, geoturismo y turismo de aventura.

Palabras clave: Actividades turísticas; Ecoturismo; Sostenibilidad; Sendero; Senhora do Carmo.

\section{INTRODUÇÃo}

Durante muito tempo os recursos naturais foram considerados bens inesgotáveis, com os quais o desenvolvimento econômico poderia ocorrer indiscriminadamente, sem maiores preocupações. Entretanto, a partir da década de 1970, essa concepção foi transmutada, e as principais discussões da época passaram a se embasar na busca por alternativas que harmonizassem preservação ambiental e progresso (Machado, 1999).

Nesse contexto insere-se o turismo, atividade econômica que consiste na exploração de uma região que possui aspectos relevantes, sejam eles naturais, histórico-culturais ou geográficos (Brasil, 2010b), dessa forma, para atender às diversas preferências, o turismo pode ser subdividido em modalidades que procuram se adequar às peculiaridades que o local apresenta.

De acordo com Liccardo (s.d.), uma das variantes dessa modalidade que mais cresce no Brasil é o geoturismo, compreendido como a associação de recursos naturais e geológicos recentemente estudado e aplicado em vários parques, como o Grand Canyon National Park (EUA), o parque nacional do Iguaçu (PR) e Unidades de Conservação (UC). Esse modelo de turismo tem como objetivo despertar o interesse de pessoas que desejam conhecer os aspectos geológicos e geomorfológicos de um determinado local. Para Silva (2004), a geologia pode contribuir significativamente para impulsionar o processo evolutivo com informações únicas a respeito do meio ambiente que trazem subsídios para a cultura e educação ambiental.

A região da Serra dos Alves, pertencente ao distrito de Senhora do Carmo Itabira (MG) -, é um local procurado por turistas, principalmente por conta de suas cachoeiras. Entretanto, os nativos do povoado podem ser impactados negativamente por essa atividade, especialmente no que se refere à tranquilidade, característica marcante de regiões afastadas de centros urbanos.

Dessa forma, este trabalho visa a caracterizar aspectos que podem interferir positivamente no turismo da região, além de verificar a infraestrutura existente para turistas, apresentando informações concernentes ao planejamento turístico sustentável dessa localidade. 


\section{CONSIDERAÇÕES METODOLÓGICAS}

Para fazer a caracterização turística de alguns recursos da região da Serra dos Alves, foram analisados três aspectos gerais: infraestrutura, indicadores biofísicos e potencial turístico. Salienta-se que quatro parâmetros para avaliar o percurso das trilhas foram adotados, como disposto no Quadro 1.

Quadro 1 - Grau de dificuldade associado ao acesso utilizado para análise das trilhas na região de Serra dos Alves (MG)

\begin{tabular}{|l|l|}
\hline Grau de dificuldade & Características \\
\hline Fácil & Trilha plana e bem marcada \\
\hline Moderado & Trilha levemente inclinada \\
\hline Difícil & Trilha inclinada \\
\hline Muito difícil & Trilha extremamente inclinada \\
\hline & Fonte - Oliveira (2015)
\end{tabular}

Existência de sinalização no local, grau de dificuldade do percurso das trilhas e eventuais particularidades em sua extensão - como travessias de rio e presença de pontes, por exemplo - foram avaliados para caracterizar a infraestrutura do local. Por outro lado, foram observadas questões como cobertura vegetal, processos erosivos e possíveis danos aos atrativos para abarcar indicadores biofísicos. Por fim, as modalidades de turismo foram qualificadas, a fim de notar quais poderiam ser desenvolvidas nas nove trilhas que percorrem a região da Serra dos Alves, levando em conta algumas singularidades do local, como paisagem e atrativos.

Conforme a metodologia de hierarquização aplicada pelo Ministério do Turismo (Brasil, 2007) e proposta pela Organização Mundial do Turismo (OMT) e pelo Centro Interamericano de Capacitação Turística (Cicatur), os atrativos da região da Serra dos Alves foram avaliados. A partir dessa análise, conjecturou-se certo grau de importância aos pontos turísticos por meio da categorização expressa no Quadro 2.

Quadro 2 - Hierarquização para grau de potencial de atratividade

\begin{tabular}{|c|c|}
\hline Hierarquia & Características \\
\hline 3 (Alto) & $\begin{array}{l}\text { É todo atrativo turístico excepcional e de grande interesse, } \\
\text { com significação para o mercado turístico internacional, } \\
\text { capaz de, por si só, motivar importantes correntes de } \\
\text { visitantes, atuais e potenciais. }\end{array}$ \\
\hline 2 (Médio) & $\begin{array}{l}\text { Atrativos com aspectos excepcionais de um país, capazes } \\
\text { de motivar uma corrente atual ou potencial de visitantes } \\
\text { estrangeiros ou do próprio país, em conjunto com outros } \\
\text { atrativos localizados nas proximidades. }\end{array}$ \\
\hline 1 (Baixo) & $\begin{array}{l}\text { Atrativos com algum aspecto expressivo, capazes de } \\
\text { interessar visitantes oriundos de lugares no próprio país, } \\
\text { que tenham chegado à área por conta de outras motivações } \\
\text { turísticas, ou capazes de motivar fluxos turísticos regionais e } \\
\text { locais (atuais e potenciais) }\end{array}$ \\
\hline
\end{tabular}


Quadro 2 - Continuação

\begin{tabular}{|l|l|}
\hline Hierarquia & Características \\
\hline 0 (Nenhum) & $\begin{array}{l}\text { Atrativos sem mérito suficiente, mas que formam parte do } \\
\text { patrimônio turístico como elementos que complementam } \\
\text { outros de maior hierarquia. Podem motivar correntes } \\
\text { turísticas locais, em particular a demanda de recreação } \\
\text { popular. }\end{array}$ \\
\hline
\end{tabular}

Fonte - Ministério do Turismo (2007)

Logo após conferir valor à hierarquia para o potencial de atratividade, foram analisados outros fatores que contribuem para a classificação de cada atrativo, dispostos no Quadro 3.

Quadro 3 - Requisitos para a classificação de atrativos turísticos

\begin{tabular}{|l|l|}
\hline Requisito & Características \\
\hline Representatividade & $\begin{array}{l}\text { Estabelecido a partir das peculiaridades do atrativo: } \\
\text { quanto mais semelhante a outros pontos turísticos, menos } \\
\text { atraente é. }\end{array}$ \\
\hline $\begin{array}{l}\text { Estado de conservação da } \\
\text { paisagem }\end{array}$ & $\begin{array}{l}\text { Aferir, a partir do método de observação, o nível de } \\
\text { conservação em que se encontra a paisagem. }\end{array}$ \\
\hline Sinalização & $\begin{array}{l}\text { Verificar a existência de sinalização adequada que indica } \\
\text { os pontos turísticos do local. }\end{array}$ \\
\hline Acesso & $\begin{array}{l}\text { Confere as condições das vias, assim como seu grau de } \\
\text { dificuldade. }\end{array}$ \\
\hline
\end{tabular}

Fonte - Ministério do Turismo (2007, adaptado)

Por consequência, criou-se a matriz de hierarquização, com valores atribuídos que variam de zero a três, a fim de qualificar o nível que cada atributo turístico possui, segundo os critérios de avaliação utilizados nesta pesquisa (Quadro 4).

Quadrro 4 - Matriz de hierarquização para classificação de atrativos turísticos

\begin{tabular}{|l|l|l|l|l|}
\hline Critérios & Valores & & & \\
\hline $\begin{array}{l}\text { Potencial de } \\
\text { atratividade }\end{array}$ & 0 (nenhum) & 1 (baixo) & 2 (médio) & 3 (alto) \\
\hline $\begin{array}{l}\text { Sinalização } \\
\text { Péssima }\end{array}$ & Regular & Boa & Ótima \\
\hline Acesso & Extremamente & Difícil & Moderado & Fácil \\
\hline $\begin{array}{l}\text { Estado de } \\
\text { conservação } \\
\text { da paisagem }\end{array}$ & Péssimo & Regular & Bom & Ótimo \\
\hline Representatividade & Nenhuma & $\begin{array}{l}\text { Elemento } \\
\text { bastante } \\
\text { comum }\end{array}$ & $\begin{array}{l}\text { Pequeno grupo } \\
\text { de elementos } \\
\text { similares }\end{array}$ & $\begin{array}{l}\text { Elemento } \\
\text { singular, raro }\end{array}$ \\
\hline
\end{tabular}

Fonte - Ministério do Turismo (2007, adaptado) 
Ressalta-se que foi atribuído peso dois aos quesitos "representatividade" e "potencial de atratividade", tendo em vista que têm maior relevância na categorização (Brizolla, 2008). A soma máxima da classificação de pontos turísticos é 21, portanto, quanto mais próximo a este número, maior a significância daquele atrativo turístico.

\section{TURISMO E SUSTENTABILIDADE}

\section{Aspectos teóricos e conceituais}

Cada vez mais observa-se necessidade de incorporar o homem aos ambientes naturais, de maneira que essa inter-relação seja encarada com maior empenho e profundidade, contribuindo para a manutenção do meio ambiente e desenvolvimento econômico, social e cultural de um determinado local (Hübner, Bahia, Fortes \& Ferreira, 2008; Vilas Boas \& Dias, 2010).

Para que a relação entre ser humano e natureza seja estabelecida de maneira efetiva, o turismo tem sido empregado como foco central para resgate e manutenção social, cultural e ambiental de certa localidade, podendo ser agente influenciador na proteção do meio ambiente (Zamignan \& Sampaio, 2010). Nessa acepção, pode ser compreendido como uma atividade em que fragilidades e peculiaridades de um local são adaptadas, com a possibilidade de desdobramento em várias modalidades, desde que sejam adequadas à identidade e variáveis encontradas no ambiente (Brasil, 2010b).

Em função de seu crescimento, a atividade turística está se tornando especializada nas áreas: rural, ecológica, cultural, religiosa, de aventura, náutica, de negócios, gastronômica, para a terceira idade, infantil etc. (Bueno, et al., 2011). Destaca-se que o conceito de ecoturismo pode ser entendido como forma de associar conservação ambiental ao desenvolvimento de comunidades, tomando sustentabilidade como fator predominante (Brasil, 2010a). Nesse sentido, segundo Felizardo e Crispim (2011), o ecoturismo corresponde a uma modalidade voltada para pequenos grupos que buscam valorizar e conservar meio ambiente, cultura e estética do local visitado. Por isso, possui característica própria relacionada à prestação do serviço turístico, uma vez que é comumente desenvolvido em regiões com grande potencial ecológico.

O turismo comunitário, ou turismo de base comunitária, pode ser compreendido como aquele em que as comunidades, de modo associativo, organizam arranjos produtivos locais, detendo o controle efetivo de terras e atividades econômicas relacionadas à atividade turística (Grimm \& Sampaio, 2011). De forma semelhante, para o Ministério do Turismo (Brasil, 2010b), está relacionado aos indivíduos de uma comunidade que se reúnem de forma diferenciada, buscando meios para a sobrevivência econômica mediante a união da atividade turística a fatores como defesa do meio ambiente e valorização da forma de vida e cultura.

Por sua vez, o turismo de aventura é definido por seus resultados incertos, assim, o desconhecimento do desfecho da atividade é recompensado pela adrenalina e experiência de enfrentar riscos e medos, habituais na vida de muitas pessoas (Brasil, 2008). Dessa forma nota-se que, de uma maneira geral, essa modalidade 
baseia-se no contato direto com a natureza, fazendo com que a busca pela tranquilidade e, ao mesmo tempo, pela emoção seja alcançada.

O conceito de turismo geológico foi apresentado inicialmente por Hose (1995 apud Rodrigues, 2009), que argumenta que essa modalidade visa ao fornecimento de serviços que facilitem ao turista interpretar e adquirir conhecimento para melhor compreender a geologia e geomorfologia de um determinado local, bem como apreciar os recursos paisagísticos. Assim, os aspectos geológicos de uma determinada região podem ser empregados no desenvolvimento do turismo local, favorecendo a economia da região, enquanto proporciona o conhecimento que concerne à história geológica e apreciação turística.

\section{Impactos do turismo e importância das políticas públicas}

O turismo, mais do que uma atividade que proporciona descanso, conhecimento e lazer ao visitante, manifesta o desempenho econômico ao propiciar análise, crescimento e movimentação de capital, ou seja, torna-se ponto relevante no mundo dos negócios (Oliveira, 2007). Quando o cunho social é envolvido, o turismo estabelece a interação entre pessoas com culturas e níveis socioeconômicos diferentes da população residente, o que pode causar impactos negativos nas relações, tendo por fatores de interferência a duração e intensidade da atividade turística (OMT, 2001).

Silva e Rocha (2010) salientam que o simples fato de conviver com pessoas de localidades e realidades diferentes impacta o modo de viver de um grupo social por meio da exposição regular a comportamentos e estilos de vida distintos, logo pode ser fator propulsor de mudanças na cultura do local. Entretanto, a atividade turística pode contribuir consideravelmente para o desenvolvimento e valorização econômica e social das comunidades. Dessa maneira, a cultura local também é abrangida, além disso, as tradições regionais podem ser sustentadas pelo desenvolvimento do turismo (Pires, 2004).

Com relação ao cunho ambiental, Vieira Filho, Duarte e Souza (2006) apontam que o turismo em espaços naturais pode instituir a consciência ambiental e até mesmo a melhoria turística, porém, também pode acarretar problemas como a poluição do meio biótico, disposição incorreta de resíduos sólidos e efluentes líquidos, erosão e desmatamento.

Para Reis (2009), mesmo que os turistas deste século estejam mais atentos às questões ambientais, faz-se necessário um planejamento bem estruturado para o turismo local ou regional, a fim de utilizar corretamente os espaços, minimizando impactos negativos e evitando prejuízo aos recursos naturais, perda de biodiversidade e aumento da poluição.

Dessa forma, a elaboração e fundamentação de políticas públicas no âmbito das atividades turísticas são de grande importância, tendo em vista que o Estado deve cumprir seu papel de favorecimento da sociedade ao promover a conservação do meio ambiente e o desenvolvimento econômico do local de forma sustentável.

Em Minas Gerais, até o final da década de 1990, não havia sido elaborada nenhuma política pública específica para a atividade turística, havia apenas ações governamentais que antecederam a criação do Conselho Estadual de Turismo e a Superintendência de Turismo (Gomes, Silva \& Santos, 2008). 
No ano de 2003, ocorreu um marco na elaboração de políticas públicas no estado, quando o Decreto $\mathrm{n}^{\circ}$ 43.321, que estabelece critérios para a regularização e funcionamento de circuitos turísticos, foi instituído. Seu primeiro artigo descreve que:

$\S 1^{o}$ - Considerar-se-á Circuito Turístico, o conjunto de municípios de uma mesma região, com afinidades culturais, sociais e econômicas que se unem para organizar e desenvolver a atividade turística regional de forma sustentável, através da integração contínua dos municípios, consolidando uma atividade regional (Minas Gerais, 2003).

\section{A região da Serra dos Alves}

A Serra dos Alves é um vilarejo localizado no distrito de Senhora do Carmo no município de Itabira, Minas Gerais. Situado na vertente leste da Área de Proteção Ambiental (APA) Morro da Pedreira, anexa ao parque nacional da Serra do Cipó (Mapa 1).

Mapa 1 - Localização do munícipio de Itabira no âmbito do estado de Minas Gerais, com destaque para o bolsão urbano referente a Serra dos Alves e atrativos turísticos locais

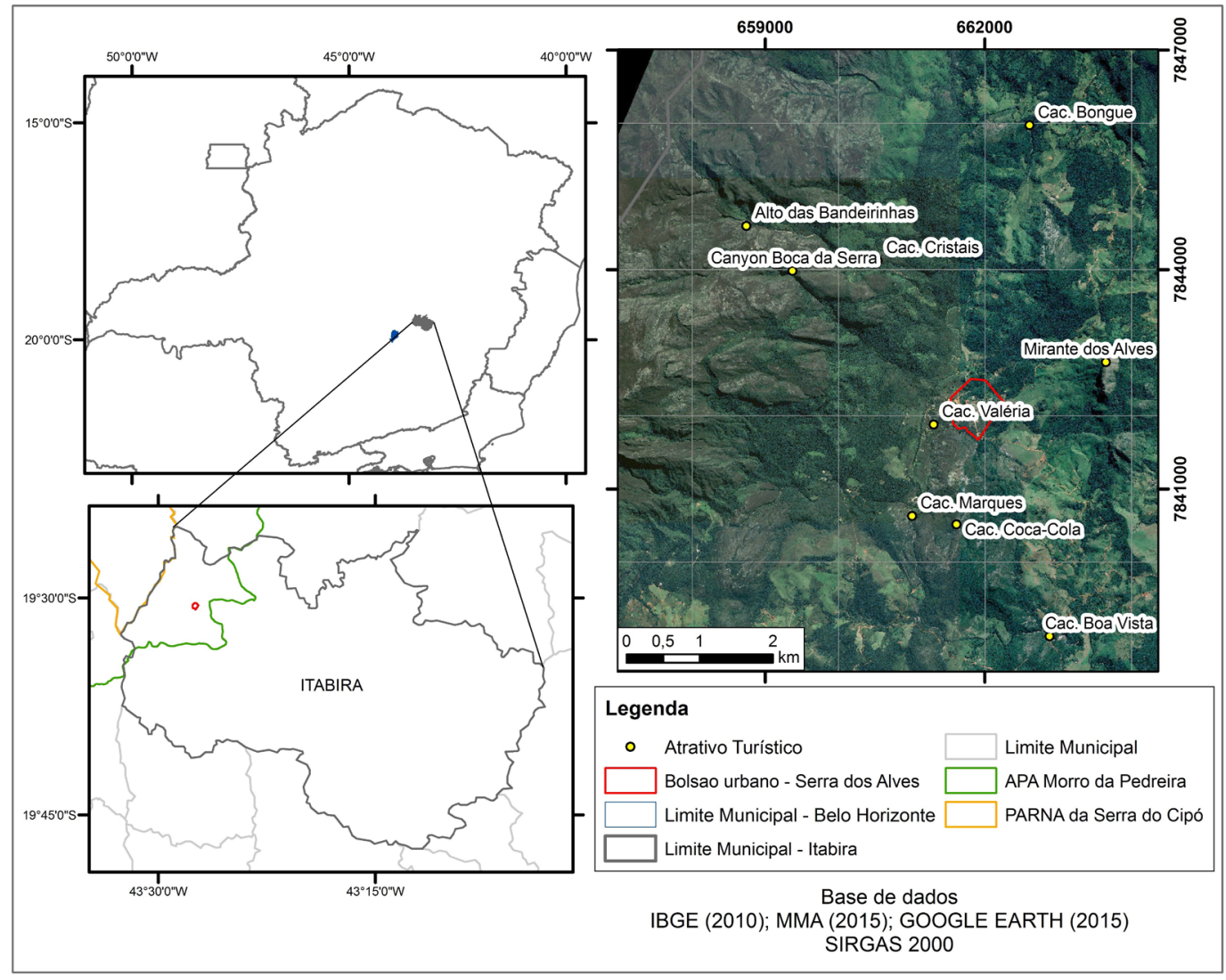

Fonte - Modificado de IBGE (2010), Ministério do Meio Ambiente (Brasil, 2016)

e Google Earth (2015) 
O parque nacional da Serra do Cipó, criado pelo Decreto Federal no 90.223 (Brasil, 1984), inserido na APA Morro da Pedreira, encontra-se localizado na porção sul da Serra do Espinhaço, e é caracterizado pela transição de dois biomas brasileiros - o cerrado e a Mata Atlântica -, apresentando grande diversidade de espécies vegetais, graças às complexidades geológicas e geomorfológicas da serra (Madeira, 2009).

0 povoado de Serra dos Alves surgiu em meados de 1850, quando os bandeirantes começaram a procurar cristais e ouro. Entretanto, os resultados da exploração portuguesa em Serra dos Alves (a exemplo de Itambé, Itabira, Serro e Conceição do Mato Dentro) não eram tão significativos quanto aqueles obtidos em Ouro Preto e Mariana, localidades onde a extração de minerais era mais fácil. Isso explica a dedicação do povoado às atividades rurais (Itabira, 2004).

Em 1866, alguns moradores doaram um hectare de terra para erguer uma capela, a primeira do vilarejo. Os próprios doadores e outros habitantes da região construíram esse oratório e, logo em seguida, o cruzeiro e o cemitério. Há também edificações com características do final do século XIX (Itabira, 2004). Hoje, o conjunto urbanístico de Serra dos Alves conta com, aproximadamente, trinta casas, sendo que apenas treze são habitadas.

A região é caracterizada por belezas naturais e aspectos culturais relevantes, como fazendas centenárias, canyons, cascatas, pontes rústicas e trilhas rurais interpretativas, o que a faz cenário de admiração para turistas cujo objetivo é preservar e valorizar reservas naturais, culturais, regionais e históricas (Braz, 2005). Porém, apesar de suas belezas naturais e histórico-culturais, Rosa (2007) discorre que, segundo os moradores, o turismo só prosperou por volta de 2003, sendo mais acentuado em comemorações tradicionais religiosas e festas juninas.

Conforme Ventura (2006), a infraestrutura local para desenvolvimento de atividades turísticas, até 2006, era deficiente, dado que não existiam estabelecimentos profissionais formais como meios de hospedagem, redes gastronômicas e sinalizações turísticas, os próprios moradores ofereciam pernoites e refeições quando necessário.

Ressalta-se ainda que um dos marcos turísticos de Serra dos Alves é seu potencial histórico-cultural, a região é caracterizada pela tradição de batuques (dança típica dos escravos), moda de quatro, marujadas e o próprio patrimônio histórico, como a igreja situada no centro do povoado (Braz, 2005).

\section{DISCUSSÃo DE RESULTADOS}

\section{Caracterização turística da região}

A partir da hierarquização, fez-se a categorização de cada trilha e ponto turístico observado, conforme a Tabela 1 . 


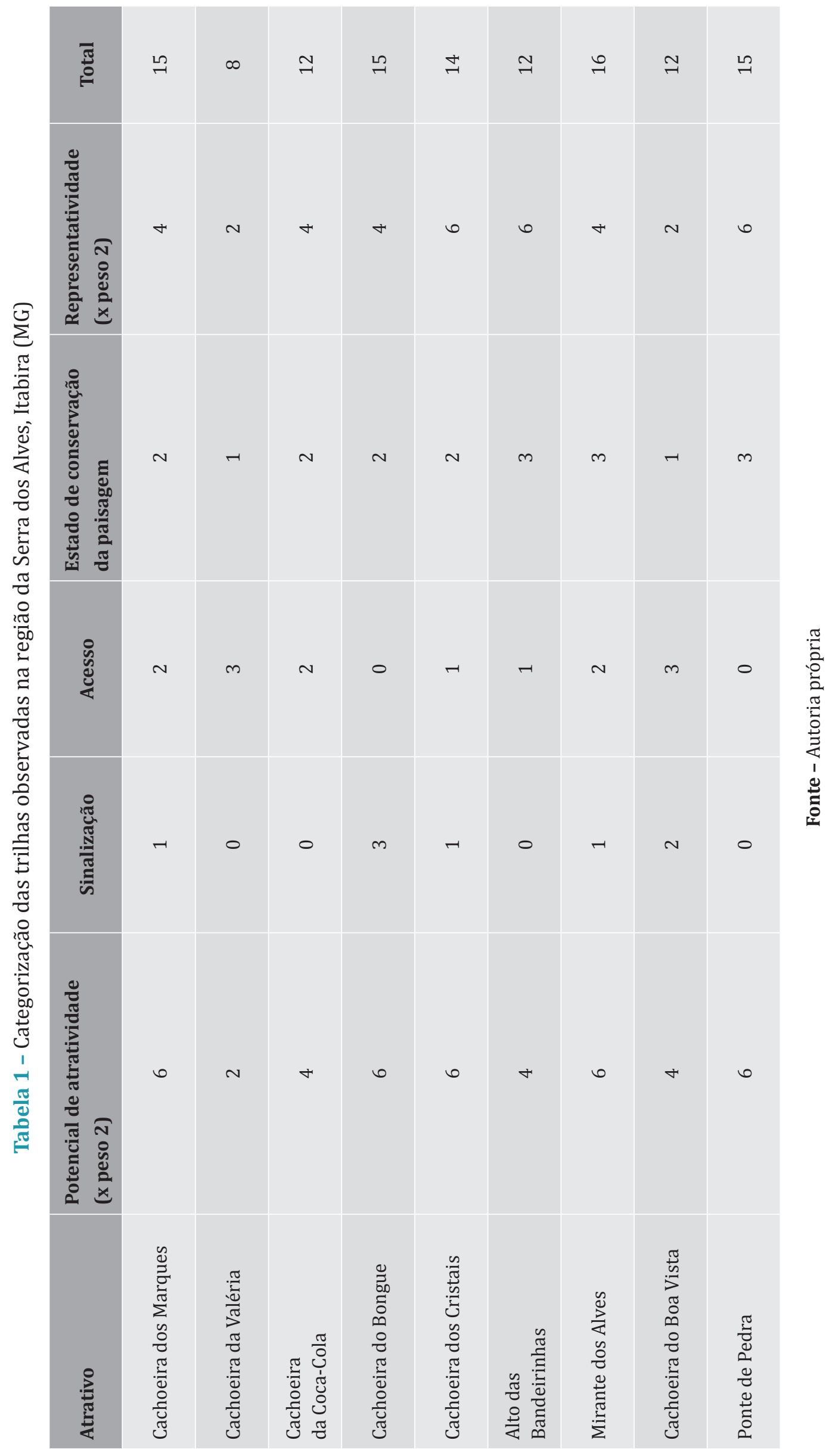


Percebe-se que a Cachoeira do Bongue, Cachoeira dos Cristais, Mirante dos Alves e Ponte de Pedra são os atrativos com maior representatividade da região. Além disso, todos se assemelham por possuir acessos classificados como moderado a extremamente difícil, o que pode ser um ponto negativo, tendo em vista que não seriam acessíveis a todos os visitantes.

No geral, a sinalização dos pontos turísticos é deficiente, sendo uma exceção a Cachoeira do Bongue, onde é possível observar a presença de placas indicativas em pontos estratégicos da estrada de acesso, facilitando a chegada à cachoeira (figuras $1 \mathrm{~A}$ e 1B). Entretanto, salienta-se que não há espaço para o estacionamento de um grande número de carros no local por conta de sua estrada estreita (Figura 1C).

Faz-se importante destacar que, apesar do grande potencial ecoturístico, a Cachoeira do Bongue é caracterizada pela quantidade expressiva de blocos de quartzito e rocha máfica de largas dimensões (Oliveira, 2015), que dificultam o deslocamento nas proximidades da queda d'água, tornando-a desaconselhável para crianças e idosos (Figura 1D).

Figura 1 - Aspectos turísticos observados ao longo do acesso para a Cachoeira do Bongue, Serra dos Alves, Itabira (MG)
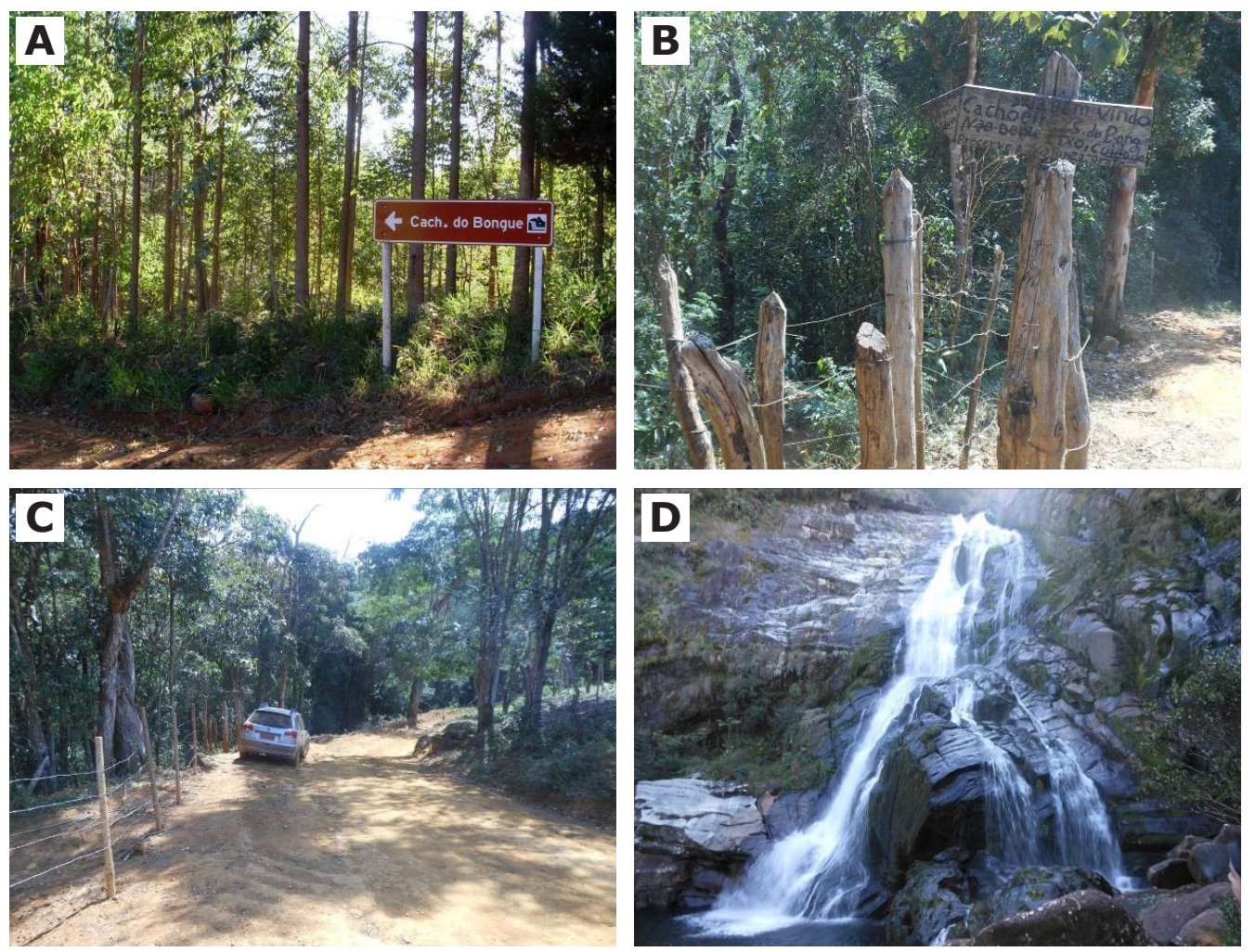

A. Placa indicativa na estrada de acesso à Cachoeira do Bongue; B. Placa indicativa do início da trilha de acesso à Cachoeira do Bongue; C. Local utilizado como estacionamento, à esquerda da estrada; D. Vista frontal da Cachoeira do Bongue

Fonte - Oliveira (2015)

Salienta-se ainda a trilha de acesso à Cachoeira dos Cristais que possui, em seus primeiros cinquenta metros, uma ponte sobre o rio Tanque em condições inadequadas para travessia, por conta de madeiras quebradas que, ao final do 
trajeto, deixam de existir (Figura 2A). Com relação à sinalização, há uma placa exibindo informações referentes à localização dos atrativos turísticos locais, porém, está deteriorada, constituindo um dos aspectos negativos para a chegada à cachoeira (Figura 2B). A primeira queda da Cachoeira dos Cristais, quando ocorre a cheia, cria poços rasos que podem ser inseridos no potencial ecoturístico, além disso, a existência de uma cascata com grande desnível possibilita que o local cachoeira também seja explorado por praticantes do turismo de aventura, como o rapel (figuras $2 \mathrm{C}$ e 2D).

Figura 2 - Aspectos turísticos observados ao longo da trilha de acesso à Cachoeira dos Cristais, Serra dos Alves, Itabira (MG)
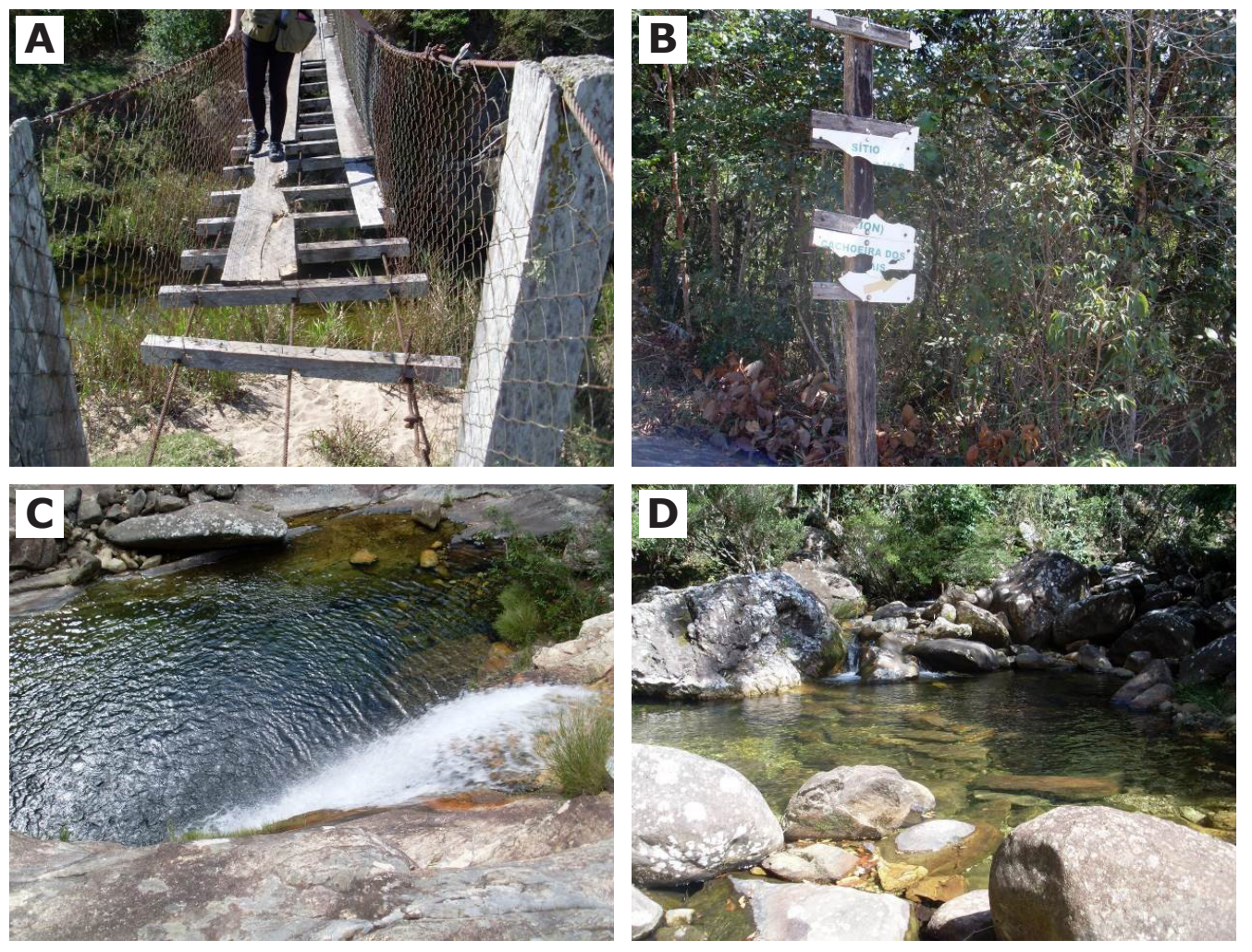

A. Ponte de madeira sobre o rio Tanque com peças danificadas e inexistentes; B. Placa danificada indicando a Cachoeira dos Cristais e Alto das Bandeirinhas; C. Primeira queda d'água da cachoeira dos cristais; D. Poços a montante da primeira queda d'água da Cachoeira dos Cristais

Fonte - Oliveira (2015)

À margem direita do rio Tanque, na Cachoeira do Boa Vista, foram observados resíduos dispostos (Figura 3A) e poços em estágio inicial de eutrofização (Figura 3B), um indicador ambiental negativo, considerando que o local é frequentemente visitado por turistas. Assim, para uma investigação mais detalhada desse ponto, indica-se a realização de trabalhos específicos com ênfase na análise da qualidade da água, buscando a avaliação de parâmetros que permitam determinar a existência de algas, bem como a presença ou ausência de coliformes termotolerantes, visando a identificar as causas para tal situação e medidas corretivas ou mitigadoras aplicáveis. 
Figura 3 - Aspectos turísticos observados na Cachoeira do Boa Vista, Itabira (MG)
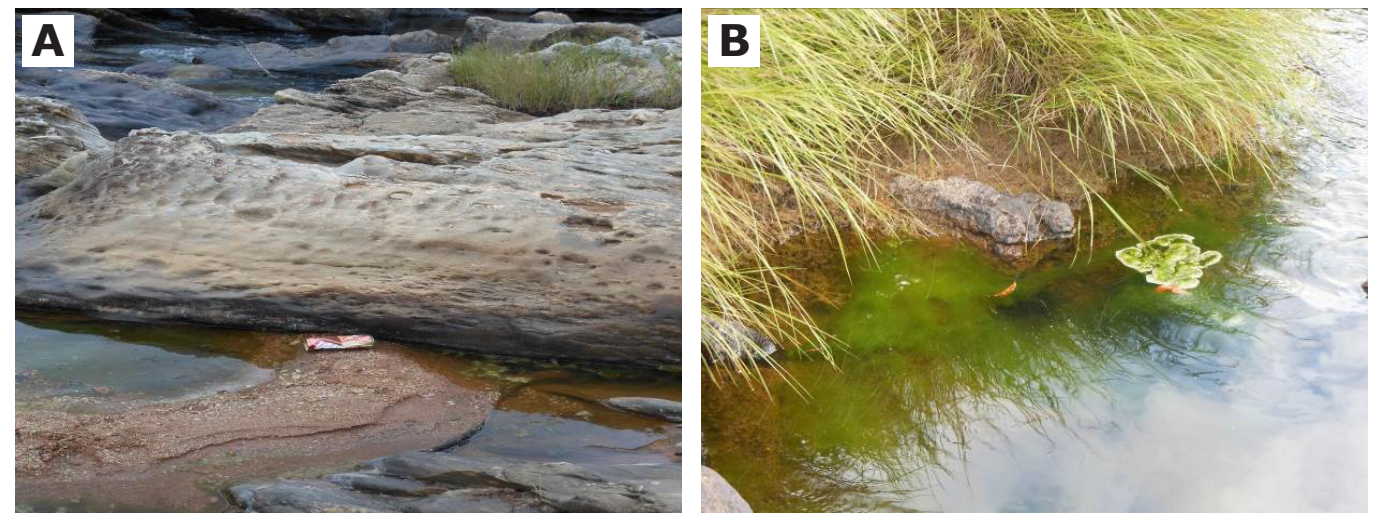

A. Lata jogada na margem direita do Rio Tanque; B. Poço com estágio inicial de eutrofização

Fonte - Oliveira (2015)

Por fim, distingue-se a Ponte de Pedra (figuras 4A e 4B) que, apesar de pouco frequentada devido ao difícil acesso, é um ponto turístico procurado por turistas de aventura e por aqueles que desejam contemplar os atrativos naturais. Além disso, possui potencial geoturístico, tendo em vista que os planos de foliação metamórfica com mergulho sub-horizontal em rocha quartzítica, esculpidos pela ação da água na estrutura geológica, foram fator fundamental para a formação desse local (Oliveira, 2015). Deste modo, o geoturismo pode ser empregado como uma ferramenta importante para a preservação e valorização do patrimônio geológico, permitindo que o turista aprecie recursos naturais abióticos com grande potencial cultural, científico e de interesse paisagístico.

Figura 4 - Aspectos turísticos observados na trilha para a Ponte de Pedra, Serra dos Alves, Itabira (MG)
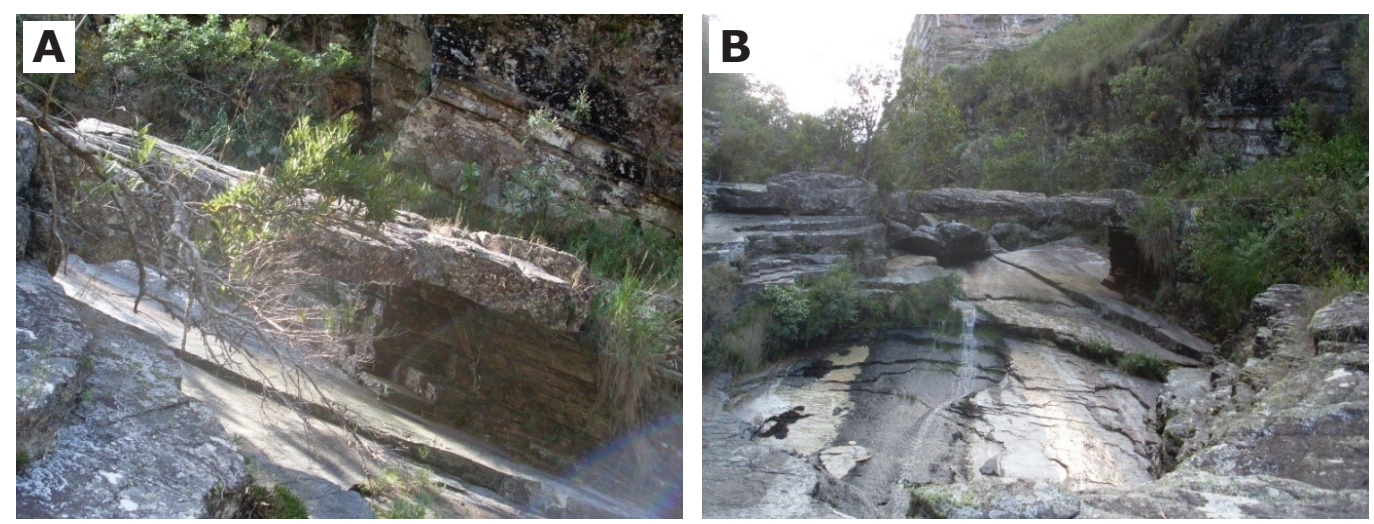

A. Vista lateral da Ponte de Pedra; B. Vista frontal da Ponte de Pedra

Fonte - Oliveira (2015)

A partir das observações, é perceptível a necessidade de conhecer melhor os pontos que possuem potencial turístico na região a fim de fazer um planejamento específico para que a atividade turística seja realizada de maneira sustentável e estruturada. 


\section{Equipamentos existentes no âmbito do planejamento turístico}

O planejamento pode ser descrito como uma concentração de esforços que visam a estabelecer objetivos e metas, assim como a maneira como podem ser alcançados, desenvolvendo diagnósticos, previsões, acompanhamentos e avaliações para que sejam construídos cenários presentes e futuros com base nas experiências e conhecimentos adquiridos ao longo do tempo (Amorim \& Umbelino, 2010).

Dessa forma, o planejamento pode ser incrementado nas atividades turísticas, constituindo mecanismo de uso fundamental para as administrações públicas municipais que acreditam no desenvolvimento do turismo de maneira sustentável (Castro \& Midlej, 2011). A partir dessa perspectiva, verificou-se a estrutura existente na região da Serra dos Alves por meio de entrevista aplicada às treze famílias residentes na comunidade, bem como observação em campo, apresentando o diagnóstico da área e as necessidades que podem ser contempladas para o desenvolvimento sustentável do turismo no local.

O bolsão urbano da Serra dos Alves é composto por, aproximadamente, trinta casas, sendo que apenas treze são resididas, contabilizando, assim, cerca de cinquenta habitantes. No vilarejo, o abastecimento de água é realizado por uma nascente ligada a uma caixa d'água localizada no centro da comunidade que a distribui para as residências. Com relação à destinação dos efluentes domésticos, os moradores informaram que o poder público disponibilizou uma fossa séptica para cada casa.

Resíduos sólidos domésticos são coletados uma vez por semana pela Empresa de Desenvolvimento de Itabira (Itaurb). Entretanto, 30\% dos residentes entrevistados optam pela queima de restos sanitários; $16 \%$ utilizam os resíduos orgânicos para alimentar animais e adubar hortas, e 4\% (um morador) realiza queima total dos resíduos sólidos. Ressalta-se que tais dados foram verificados recentemente por Sá et al. (2015).

Considerando os demais serviços estruturais, a comunidade conta com energia elétrica em todas as residências, além de serviços complementares como telefonia móvel - disponível para cerca de 78\% dos moradores entrevistados - e internet - utilizada por $15 \%$.

Com relação aos indicadores turísticos, 36\% dos entrevistados relataram que essa atividade é bastante rentável para a região, principalmente em épocas festivas e feriados prolongados, tendo em vista o aumento pela procura de produtos e serviços como biscoitos, doces e faxina. No entanto, os residentes se queixam de épocas de grande movimentação, destacadas por um dos entrevistados ao dizer que: "alguns turistas fazem muita bagunça" (sic). Outra situação, exposta por $15 \%$ dos entrevistados, foi a disposição de campings irregulares que podem despejar resíduos no solo, além de possíveis resquícios de fogo provenientes de fogueiras acesas por turistas, podendo desencadear danos à vegetação e moradores.

Ademais, foi questionado aos residentes se visitam algum ponto turístico da região. Dentre os entrevistados, $77 \%$ responderam que fazem visitas esporádicas, entre os atrativos preferenciais estão as cachoeiras do Bongue (escolha de 24\% dos moradores entrevistados), dos Marques (opção de 20\%) e dos Cristais (indicada por 17\%). 
Hoje, a região da Serra dos Alves conta com duas pousadas, dez residências alocadas para temporada, um ponto gastronômico e dois bares. Assim, ao perceber o crescimento turístico, muitos investiram para que o local contasse com equipamentos que melhorassem o atendimento aos visitantes, diferentemente do exposto por Ventura (2006) que discorre que, até aquele ano, a comunidade não possuía nenhum estabelecimento profissional formal, como meios de hospedagem e redes gastronômicas.

Com relação à oferta de equipamentos públicos, a Serra dos Alves se caracteriza por um conjunto rural, mesmo estando localizada em um bolsão urbano, dado que não há postos de saúde, bancos, farmácias e posto policial. Dessa maneira é preciso ir até o distrito de Senhora do Carmo - cerca de $15 \mathrm{~km}$ de distância quando esses serviços se fazem necessários.

Para que se obtenha desenvolvimento do turismo de forma sustentável, o município de Itabira pode contar com algumas políticas públicas envolvendo a atividade na região, atestando as assertivas de Garcia e Ashton (2006) sobre a importância do papel do Estado na instituição de políticas de abrangência turística, considerando que fundamentam adequações que incluem os âmbitos econômico, social, cultural e ambiental. No caso de Itabira, as principais políticas instituídas correspondem ao Plano Diretor, regulamentado pela Lei Municipal $\mathrm{n}^{\circ} 4.034 / 2006$ e ao Plano Municipal de Turismo.

O Plano Diretor de Itabira classifica a região como zona AIC, ou seja, Área de Interesse Cultural, estabelecendo em seu Art. 45 que este zoneamento corresponde:

às áreas pertencentes ao conjunto do Centro Histórico da sede municipal, onde se encontram edificações e espaços representativos da memória e da identidade cultural da sua sociedade, os quais devem ser protegidos individualmente e em conjuntos, assim como demais áreas e bens tombados de acordo com critérios do Conselho Consultivo Municipal de Patrimônio Histórico e Artístico de Itabira. (Itabira, 2006, Art. 45).

Para o âmbito turístico, a Prefeitura Municipal de Itabira (2014) elaborou o Plano Municipal de Turismo, discorrendo que a atividade é incipiente e vem crescendo de maneira desregrada e sem planejamento eficaz no vilarejo da Serra dos Alves. Entretanto, foi apenas nos últimos dois anos que modestas intervenções foram realizadas - por intermédio da Secretaria Municipal de Turismo - com o objetivo de gerar benefícios econômicos e sociais, intentando minimizar possíveis impactos negativos que possam ser gerados por este segmento.

Dessa forma, pode-se orientar o planejamento do turismo em bases sustentáveis no vilarejo da Serra dos Alves em três aspectos: infraestrutura geral, turismo e sustentabilidade e, dentro destes, perspectivas mais importantes, inserindo-as na matriz de Forças, Oportunidades, Fraquezas e Ameaças (Fofa).

A matriz Fofa, originalmente determinada como SWOT (Strenghts, Weaknesses, Opportunities, Threats), é uma estrutura utilizada para diagnosticar a posição estratégica de uma organização ou, neste caso, das atividades turísticas em um ambiente, tornando-se um instrumento adequado para gerenciamento e acompanhamento do turismo em determinado local (Dantas \& Melo, 2008).

No caso da APA Morro da Pedreira, foi elaborada uma matriz pelo ICMBio (Instituto Chico Mendes de Conservação da Biodiversidade) (Madeira, 2009), 
contudo, nesse trabalho, a Fofa foi estruturada no contexto das atividades turísticas na região da Serra dos Alves, conforme modelo apresentado por Barbosa Filho (2009), que pode ser verificada no Quadro 5.

Quadro 5 - Matriz Fofa no âmbito das atividades turísticas para a região da Serra dos Alves (MG)

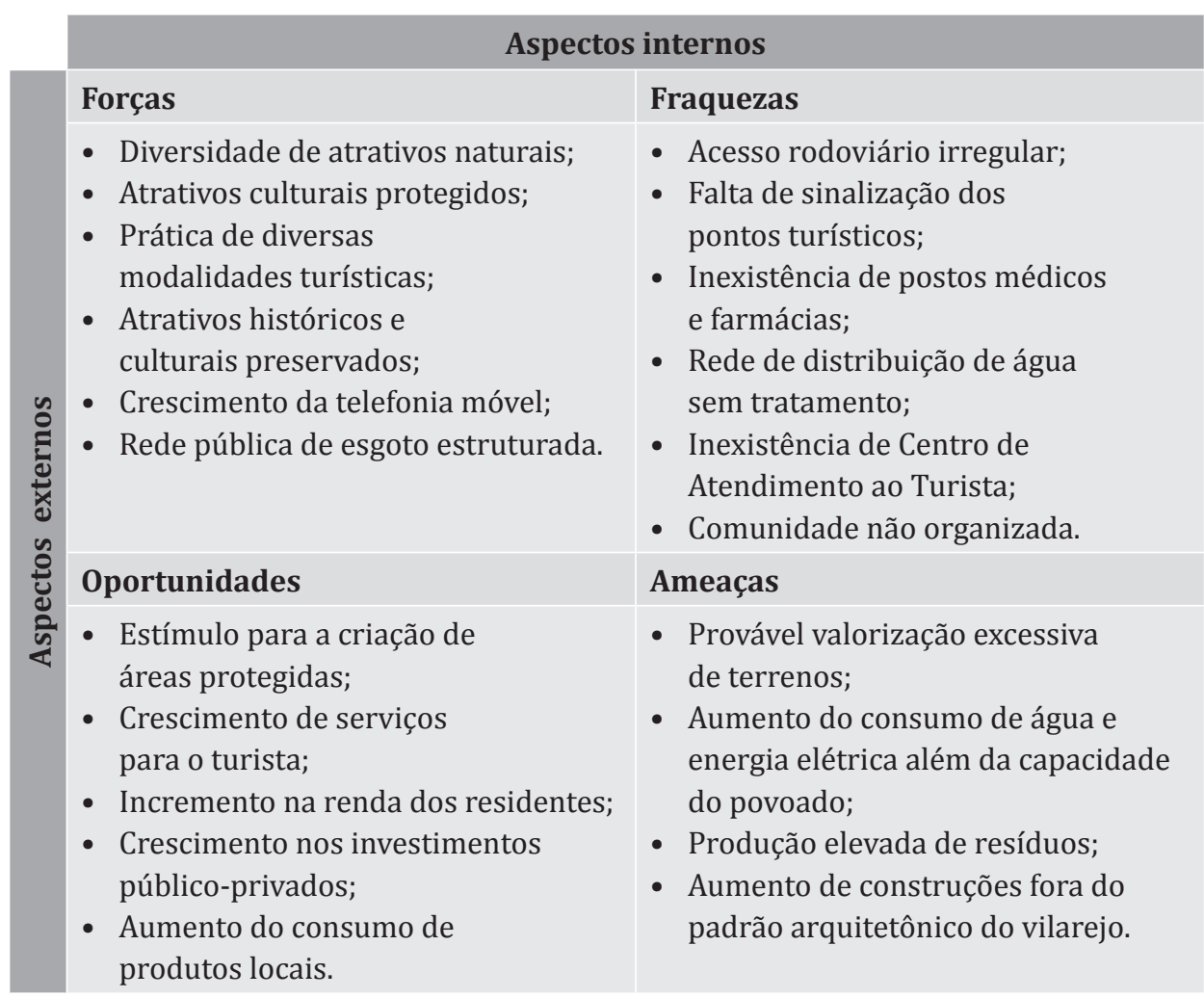

Fonte - Oliveira (2015)

Por consequência, a elaboração dessa matriz possibilita a identificação dos aspectos externos e internos relevantes que podem ser considerados em um planejamento turístico, otimizando forças e envolvendo oportunidades ao mesmo tempo em que corrige fraquezas e prepara-se para possíveis ameaças.

\section{CONSIDERAÇÕES FINAIS}

O turismo é uma atividade econômica que pode compreender elementos ambientais, histórico-culturais e sociais, necessitando, para a sua adequada implementação, de uma apropriada identificação dos impactos positivos (para que sejam aprimorados) e dos negativos (para que sejam atenuados). Ao analisar os recursos naturais presentes no vilarejo da Serra dos Alves, localizado no distrito de Senhora do Carmo, Itabira (MG), percebe-se potencial para o desenvolvimento da atividade turística na região, entretanto existem elementos desfavoráveis que podem comprometer a prática do turismo em bases sustentáveis.

Com relação à análise turística, foram identificados os principais aspectos em cada uma das trilhas, tanto positivos quanto negativos, que devem ser considerados para a promoção do turismo sustentável. De maneira geral, a região 
apresenta potencial para o desenvolvimento de diferentes modalidades turísticas, tais como o ecoturismo, turismo de aventura e geoturismo. Por outro lado, a ausência de sinalização adequada dos recursos turísticos e a má conservação das vias de acesso, representam elementos a serem ajustados para o crescimento do turismo na região.

Além disso, para que o vilarejo tire benefícios das atividades turísticas, é fundamental o levantamento das estruturas existentes como hospedagem, equipamentos públicos e pontos de gastronomia para que esses elementos também sejam contemplados no planejamento para o turismo sustentável da região. Desse modo, observou-se que os atrativos naturais são procurados com maior frequência nos fins de semana e feriados prolongados, o que pode significar aspecto negativo para os moradores locais, principalmente no que diz respeito ao abastecimento de água e aumento de resíduos sólidos, tendo em vista que tais serviços ainda são insuficientes para suprir a demanda de visitantes, que cresce a cada ano.

Nesta perspectiva, percebe-se que a conciliação entre meio ambiente e desenvolvimento é cada vez mais decorrente. A instituição de políticas públicas que estabelecem uma relação harmônica entre atividades econômicas e meio ambiente também é importante, sendo inseridos nesta perspectiva o planejamento e a gestão ambiental dos processos e impactos resultantes de atividades turísticas.

\section{REFERÊNCIAS}

AMORIM, E., \& Umbelino, J. (2010). Estrutura organizacional do processo de planejamento turístico: uma perspectiva teórica. Cultur, 4(2). Recuperado de https://goo.gl/djw17q BARBOSA FILHO, W. (2009). Gestão estratégica aplicada ao turismo: ferramentas de posicionamento estratégico direcionado à Casa das Tulhas. Patrimônio: Lazer e Turismo, 6(5), 70-94. Recuperado de https://goo.gl/8ZaZze

BRASIL. (1984, 25 de setembro). Decreto Federal n. 90.223. Cria, no estado de Minas Gerais, o parque nacional da Serra do Cipó e dá outras providências. Brasília, DF: Diário Oficial da União. Recuperado de https://goo.gl/1eX4Pp

BRASIL. Ministério do Meio Ambiente. (2016). Download de dados geográficos. Recuperado de https://goo.gl/oW9TPV

BRASIL. Ministério do Turismo. (2008). Diagnóstico do turismo de aventura no Brasil. Brasília, DF: Ministério do Turismo. Recuperado de http://201.2.114.147/bds/bds.nsf/ 80D660D9457179E6832576B80051DAEF/\$File/NT0004393E.pdf

BRASIL. Ministério do Turismo. (2010a). Ecoturismo: orientações básicas (2a ed.) Brasília, DF: Ministério do Turismo. Recuperado de https://goo.gl/jeV5bE

BRASIL. Ministério do Turismo. (2010b). Marcos conceituais. Brasília, DF: Ministério do Turismo. Recuperado de https://goo.gl/aWJsSc

BRASIL. Ministério do Turismo. (2007). Roteiros do Brasil: Módulo Operacional 7 (Programa de regionalização do Turismo). Brasília, DF: Ministério do Turismo. Recuperado de https://goo.gl/C2pz7W

BRASIL. Ministério do Turismo. (2008). Programa de qualificação à distância para o desenvolvimento do turismo. Brasília, DF: Ministério do Turismo. Recuperado de https:// goo.gl/BWQBw5 
BRAZ, G. S. (2005). Trilhas interpretativas: um turismo sustentável. (Monografia não publicada). Fundação Comunitária de Ensino Superior de Itabira, Itabira, MG.

BUENO, C., et al. (2011). Ecoturismo responsável e seus fundamentos (1aㅡ ed.). Rio de Janeiro, RJ: Technical Books.

CASTRO, F. M. M., \& Midlej, M. M. C. (2011). Planejamento turístico: análise da proposta no município de Valença (BA) no âmbito das recomendações das políticas públicas do turismo no país. Caderno Virtual de Turismo, 11(1), 18-35. Recuperado de https://goo. $\mathrm{gl} / \mathrm{LtVufw}$

DANTAS, N. G. S., \& Melo, R. S. (2008). 0 método de análise SWOT como ferramenta para promover o diagnóstico turístico de um local: o caso do município de Itabaiana/PB. $\mathrm{Ca}$ derno Virtual de Turismo, 8(1), 118-130. Recuperado de https://goo.gl/JJycYY

FELIZARDO, A., \& Crispim, J. (2011). A educação ambiental na prática do ecoturismo. In Anais do II Seminário dos Cursos de Ciências Sociais Aplicadas da Fecilcam. Campo Mourão, PR. Recuperado de https://goo.gl/pn6RXY

GARCIA, R. K. O \& Ashton, M. S. G. (2006). Gestão pública em Turismo: a necessidade de uma visão estratégica para o planejamento e a condução da atividade turística de forma sustentável. In Anais do IV Seminário de Pesquisa em Turismo do MERCOSUL. Caxias do Sul, RS. Recuperado de https://goo.gl/4pcvRj

GOMES, B. M. A., Silva, V. J., \& Santos, A. C. (2008). Políticas públicas de turismo: uma análise dos circuitos turísticos de Minas Gerais sob a concepção de cluster. Turismo em Análise, 19(2), 201-220. Recuperado de https://goo.gl/vkRiZC55.

GRIMM, I. J., \& Sampaio, C. A. C. (2011). Turismo de base comunitária: convivencialidade e conservação ambiental. Revista Brasileira de Ciências Ambientais, (19). Recuperado de https://goo.gl/vYzYeX

HÜBNER, D. B., Bahia, E. T., Fortes, M., \& Ferreira, W. R. (2008). Sustentabilidade e biodiversidade em unidades de conservação do Brasil. Reuna, 13(1), 61-67. Recuperado de https://goo.gl/5zfiaF

IBGE. (2010). Carta Internacional ao Milionésimo. Recuperado de https://goo.gl/uWuCYW

ITABIRA. (2004). Prefeitura Municipal. Dossiê de Tombamento: conjunto urbano da Serra dos Alves. Itabira, MG: Prefeitura Municipal.

ITABIRA. (2014). Prefeitura Municipal. Plano Municipal de Turismo 2014-2017. Itabira, MG: Prefeitura Municipal.

ITABIRA. (2006, 16 de novembro). Prefeitura Municipal. Lei Municipal no 4.034. Institui o plano diretor de desenvolvimento sustentável de Itabira e dá outras providências. Itabira, MG: Diário Oficial do município de Itabira.

LICCARDO, A. (s.d.) Geoturismo. Curitiba, PR: UFPR. Recuperado de https://goo.gl/SUtPZW

MACHADO, L. M. C. P. (1999). A percepção do meio ambiente como suporte para a educação ambiental. In Pompêo, M. L. M. (Org.). Perspectivas na limnologia do Brasil. São Luís, MA: União. Recuperado de https://goo.gl/r8VTSD

MADEIRA, J. A. (2009). (Org.). Plano de manejo: Parque Nacional da Serra do Cipó e Área de Proteção Ambiental Morro da Pedreira. Brasília, DF: ICMBio. Recuperado de https:// goo.gl/8NnKQA

MINAS Gerais. (2003, 8 de maio). Decreto no 43.321. Dispõe sobre o reconhecimento dos circuitos turísticos e dá outras providências. Belo Horizonte, MG: Diário Oficial de Minas Gerais. Recuperado de https://goo.gl/BR6ypu 
OLIVEIRA, R. S. (2015). Contribuições geológicas para o desenvolvimento do turismo sustentável na Serra dos Alves em Senhora do Carmo, distrito de Itabira-MG (Monografia não publicada). Fundação Comunitária de Ensino Superior de Itabira, Itabira, MG.

OMT. (2001). Introdução ao Turismo. São Paulo, SP: Roca.

PIRES, E. V. (2004). Impactos socioculturais do turismo sobre as comunidades receptoras: uma análise conceitual. Caderno Virtual do turismo, 4(3). Recuperado de https:// goo.gl/mBQQrE

REIS, J. R. (2009). Aula 9: Os impactos causados pelo Turismo no Meio Ambiente. In Teoria Geral do Turismo (pp. 177-194). Rio de Janeiro, RJ: Fundação CECIERJ. Recuperado de https://goo.gl/DGVsuQ

RODRIGUES, J. C. (2009). Geoturismo: uma abordagem emergente. In Neto de Carvalho, C., \& Rodrigues, J. C. (Orgs.). Geoturismo \& Desenvolvimento Local (pp. 38-61). Castelo Branco, PT: Câmara municipal de Idanha-a-Nova. Recuperado de https://goo.gl/aQYaYF

ROSA, L. D. (2007). A importância da atividade turística para o desenvolvimento do povoado de Serra dos Alves, Itabira/MG (Monografia não publicada). Fundação Comunitária de Ensino Superior de Itabira, Itabira, MG.

SÁ, A. D., et al. (2015). Promoção de saneamento básico na zona rural: um estudo em comunidades do município de Itabira, Minas Gerais (Projeto de extensão não publicado). Fundação Comunitária de Ensino Superior de Itabira, Itabira, MG.

SILVA, O. V., \& Rocha, G. C. G. (2010). Impactos positivos e negativos da prática de turismo em ambientes rurais. Revista Científica Eletrônica de Turismo, 7(13). Recuperado de https://goo.gl/ErZ14j

VENTURA, H. L. C. (2006). O turismo e a sua interface com Áreas de Proteção Ambiental (Monografia não publicada). Fundação Comunitária de Ensino Superior de Itabira, Itabira, MG.

VIEIRA Filho, N., Duarte, G., \& Souza, T. R. (2006). 0 impacto do turismo sobre a arte e o artesanato em Tiradentes, Minas Gerais. In Anais do Seminário de Pesquisa em Turismo do Mercosul, Caxias do Sul, RS. Recuperado de https://goo.gl/m4oMaS

VILAS Boas, M. H. A., \& Dias, R. (2010). Biodiversidade e turismo: o significado e importância das espécies-bandeira. Turismo \& Sociedade, 3(1), 91-114. Recuperado de https:// goo.gl/NY5uLr

ZAMIGNAN, G., \& Sampaio, C. A. C. (2010). Turismo de base comunitária como perspectiva para a preservação da biodiversidade e de modos de vidas de comunidades tradicionais: a experiência da micro-bacia do Rio Sagrado, Morretes (PR). In V Encontro Nacional da ANPPAS, Florianópolis, SC. Recuperado de https://goo.gl/xnxUds

Recebido em: $15 / 08 / 2016$

Aprovado em: 25/03/2017 